\section{Discussion}

The association of a constitutional deletion of the terminal end of $q 22$ (band $q 13 \cdot 3 \rightarrow$ qter) with multiple meningiomas is of great interest. We suspected the presence of intracranial cysts in the patient because of his symptoms, the results of CT scan, and EEG examination. However, meningeal hypoplasia and dysplasia, including meningiomatosis, and an anomalous cyst composed of meningocytic elements were found at necropsy. As is well known, 22q- or monosomy 22 can be commonly observed in cultured meningioma cells. ${ }^{3}$ Recently, the relationship between constitutional and somatic chromosomal changes in patients with retinoblastoma ${ }^{6}$ and Wilms's tumour $^{7}$ has been shown. These findings tend to support a close relationship between a partial deletion of chromosome 22 and meningeal malformations including tumours. The karyotype of the tumour cells was not investigated in our patient. However, the presence of a constitutional ring chromosome 22 , which may lack the distal end of the long arm, supports the suggestion of Zankl and Zang $^{3}$ that genetic information involved in the control of cell proliferation is located in this segment. Recently, the human homologue of the simian sarcoma virus oncogene, c-sis, has been assigned to $22 \mathrm{q} .{ }^{8}$ The proto-oncogene c-sis might be related to the genesis of meningiomas. Furthermore, these chromosome changes may be tissue specific, in the sense that they may predispose specifically to meningiomas, because necropsy revealed no neoplasia in other organs of our patient.
In conclusion, the findings described in this paper suggest that constitutional deletions of chromosome 22 may predispose to tumourigenesis of meningiomas. To confirm this, further neuropathological studies of patients with $22 \mathrm{q}-$ or monosomy 22 are required. Clinical examination for congenital anomalies and chromosome analysis should be carried out in all patients with meningiomas.

\section{References}

1 Hunter AGW, Ray M, Wang HS, Thompson DR. Phenotypic correlations in patients with ring chromosome 22. Clin Genet 1977;12:239-49.

2 Stoll C, Roth MP. Segregation of a 22 ring chromosome in three generations. Hum Genet 1983;63:294-6.

3 Zankl H, Zang KD. Cytological and cytogenetic studies on brain tumors. IV. Identification of the missing $G$ chromosome in human meningiomas as No 22 by fluorescence technique. Humangenetik 1971;14:167-79.

${ }^{4}$ Kondo I, Hamaguchi H, Nakajima S, Haneda T. A cytogenetic survey of 449 patients in a Japanese institution for the mentally retarded. Clin Genet 1980;17:177-82.

5 Seabright M. A rapid banding technique for human chromosomes. Lancet 1971;ii:971-2.

' Cavenee WK, Dryja TP, Phillips RA, et al. Expression of recessive alleles by chromosomal mechanisms in retinoblastoma. Nature 1983;305:779-84.

${ }^{7}$ Koufos A, Hansen MF, Lampkin BC, et al. Loss of alleles at loci on human chromosome 11 during genesis of Wilms' tumour. Nature 1984;309:170-2.

${ }^{8}$ Swan DC, McBride OW, Robbins KC, Keithley DA, Reddy EP, Aaronson SA. Chromosomal mapping of the simian sarcoma virus onc gene analogue in human cells. Proc Natl Acad Sci USA 1982;79:4691-5.

Correspondence and requests for reprints to $\mathrm{Dr}$ Ikuko Kondo, Department of Human Genetics, Institute of Basic Medical Sciences, University of Tsukuba, Ibaraki-ken 305, Japan.

\title{
Prenatal diagnosis and follow up of a child with a complex chromosome rearrangement
}

\author{
MARK H BOGART, CHRISTY L BRADSHAW, OLIVER W JONES, \\ AND JOHN E SCHANBERGER \\ Division of Medical Genetics, Department of Medicine, University of California, San Diego, La Jolla, \\ California 92093, USA.
}

SUMMARY A case of de novo, apparently balanced, three way exchange by translocation plus a pericentric inversion is described. The karyotype is $46, \mathrm{XX}, \mathrm{t}(6 ; 11)(\mathrm{p} 21 ; \mathrm{q} 21), \mathrm{t}(11 ; 21)$ $(\mathrm{q} 21 ; \mathrm{p} 13)$,inv(6)(p21q11) and was ascertained through second trimester amniocentesis. The structural rearrangements appear balanced.

Received for publication 20 November 1984

Revised version accepted for publication 5 February 1985.
The child was phenotypically normal at birth. Growth and motor development were normal until 30 months, at which time linear growth dropped below the 5th centile. In addition, there was delayed speech development at 2 years of age.

As far as we can determine, this is the first report of a three chromosome exchange including a pericentric inversion ascertained through genetic amniocentesis. 


\section{Case report}

The mother was 30 years of age and the father 31 at the time of her pregnancy. There had been two previous normal term pregnancies followed by a pregnancy which produced a term stillborn anencephalic infant. Genetic amniocentesis was performed because of the pregnancy with anencephaly and parental concern. Ultrasound before amniocentesis at 16 weeks' gestation was unremarkable. Alphafetoprotein analysis was within normal limits for 16 weeks' gestation. Karyotype analysis of cultured amniotic fluid cells revealed the karyotype $46, X X, t(6 ; 11)$ (p21;q21),t(11;21) (q21;p13),inv(6) (p21q11) (fig 1). Subsequent chromosome studies on peripheral blood samples from each parent showed normal karyotypes in both. Repeat amniocentesis confirmed the original karyotype. After counselling and review of all available data, the parents elected to continue the pregnancy. The infant was born at term by vaginal delivery. Labour and delivery were uncomplicated.

Apgar scores were 9 at one and five minutes. The head circumference was on the 50th centile, the length on the 50th centile, and the weight on the 25 th centile. No dysmorphic features were noted. Peripheral blood chromosome analysis confirmed the karyotype. During the first year of life, transient episodes of sucrose intolerance were documented.
During the first 30 months, linear growth remained between the 5th and 10th centiles. Afterwards linear growth dropped to less than the 5th centile with weight remaining at the 35 th centile and head circumference at the 50th centile. Recently, linear growth rate has returned to the 5 th centile. No symptoms have been associated with the transient decline in linear growth. CT scan was normal and no deficiency in growth hormone was found. Developmental milestones have been normal: however, her first words were spoken at $2 \frac{1}{2} 2$ years and at $23 / 4$ years there are no complete sentences.

\section{Discussion}

It has been possible to identify 45 pregnancies from previous publications concerning kindreds with complex chromosome structural rearrangements occurring either as a new mutation or as a familial multichromosome structural rearrangement. ${ }^{1-17}$ Both de novo and familial structural rearrangements produced abnormal pregnancies. Fourteen of the 45 pregnancies (approximately $31 \%$ ) produced liveborn infants who were phenotypically normal, either with a normal karyotype or with a balanced karyotype identical to one parent. Fifteen liveborns (approximately 33\%) with multiple anomalies also had unbalanced complex translocations. Fifteen pregnancies (approximately 33\%) ended as an

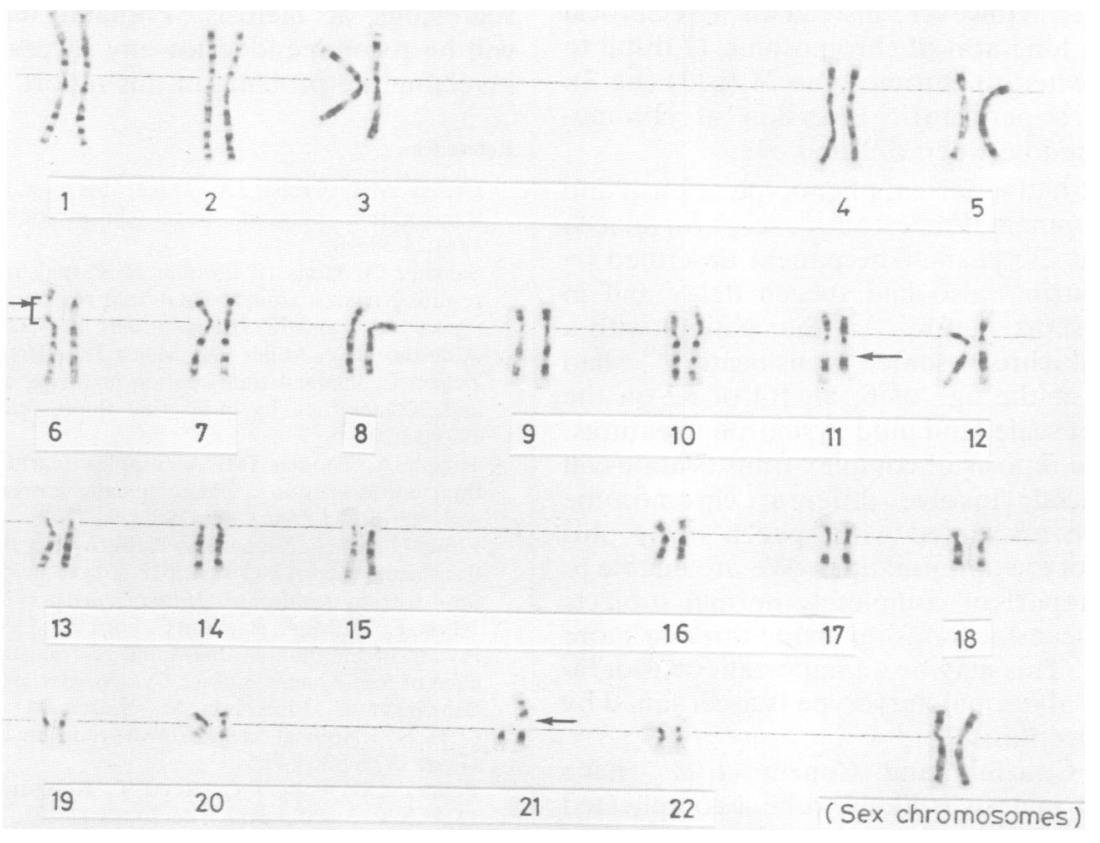

FIG 1 Karyotype showing complex chromosome rearrangement involving chromosomes 6, 11, and 21 . 


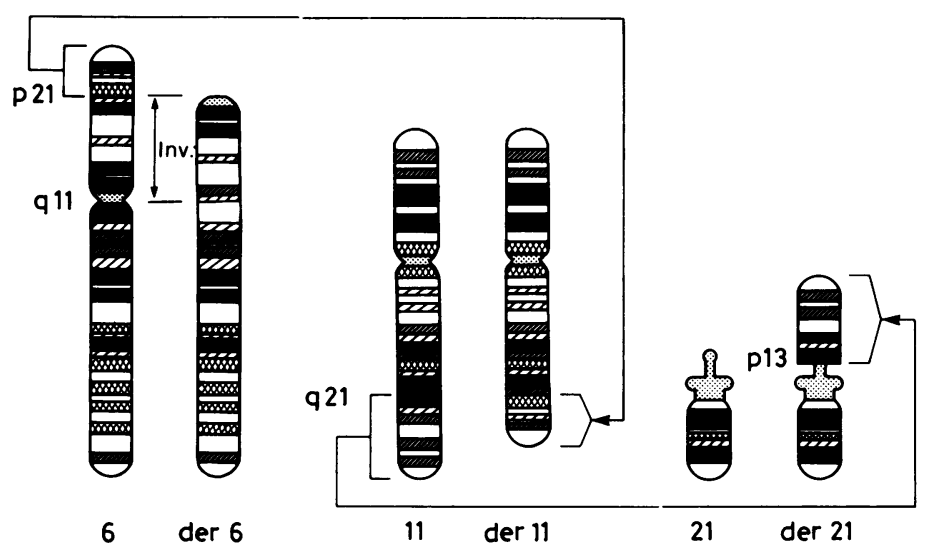

FIG 2 Schematic drawing of chromosomes 6,11 , and 21 showing breakpoints leading to the rearranged chromosomes, der(6), der(11), der (21).

abortus or stillborn, but no cytogenetic studies were done in these pregnancies. One liveborn with multiple anomalies had an apparently balanced karyotype consisting of a complex four chromosome rearrangement including a pericentric inversion. ${ }^{16}$ Therefore, approximately two-thirds of pregnancies with familial or de novo multichromosome rearrangements had an abnormal outcome.

In the case presented here, the short arm of chromosome 6 distal to breakpoint p21 is translocated to the long arm of chromosome 11 at breakpoint q21. However, instead of a reciprocal exchange, the long arm of chromosome 11 distal to q21 is translocated to chromosome 21 (p13) (fig 2). Additionally, a pericentric inversion of chromosome 6 occurred between p21 and q11.

Our patient had a normal phenotype at birth and normal developmental milestones except for speech delay noted at $2 \frac{1}{2}$ years. The patient described by Watt and Couzin ${ }^{18}$ also had speech delay and in addition had short stature. Another patient with a complex multichromosome translocation ${ }^{19}$ had speech delay at the age of 6 , an IQ of 82 on the Stanford-Binet scale, and mild dysmorphic features. The three case reports of complex translocations all appear balanced, involve different chromosome pairs, and are associated with speech delay plus variable phenotype abnormalities. We are unable to identify any report of completely normal subjects with de novo translocations involving three or more chromosomes. This may be an important consideration when the abnormal karyotype is ascertained by genetic amniocentesis.

Watt and Couzin ${ }^{18}$ and Couzin et al ${ }^{19}$ have suggested that meiosis is likely to be a complicated event in multichromosome translocations. There are at least five breakpoints in the three chromosome exchange described here, including the pericentric inversion. Meiotic configurations will involve chromosome 11 with chromosome 6 or 21 . The addition of the pericentric inversion on chromosome 6 further raises the risk for duplication and deficiencies in gametes.

The risk for abnormal reproductive outcome in carriers of complex rearrangements appears to be increased but not absolute. It might be expected that a complex translocation which includes a pericentric inversion carries an even greater risk for abnormal segregants at meiosis. Prenatal fetal assessment will be recommended for any successful pregnancy involving the proband in this report.

\section{References}

1 Creasy MR, Crolla JA, Daker MG. A familial reciprocal translocation between three chromosomes. Humangenetik 1974;24:303-8.

2 Sanchez O, Yunis JJ, Escobar JI. Partial trisomy 11 in a child resulting from a complex maternal rearrangement of chromosomes 11, 12 and 13. Humangenetik 1974;22:59-65.

3 Alderdice PW, Miller OJ, Miller DA, Breg WR, Gendel E, Zelson C. Familial translocation involving chromosomes 6, 14 and 20 identified by quinacrine fluorescence. Humangenetik 1971;13:205-9.

4 Joseph A, Thomas IM. A complex rearrangement involving three autosomes in a phenotypically normal male presenting with sterility. J Med Genet 1982;19:375-7.

5 Fujita H, Abe T, Yamamoto K, Furuyama JI. Possible complex translocation $\mathrm{t}(9 ; 14 ; 13)(\mathrm{q} 12 ; \mathrm{p} 1$ ?; $\mathrm{q} 31)$ in mother of a child with 9p- trisomy syndrome. Humangenetik 1974;25:83-92.

6 Nuzzo F, Marini A, Baglioni C, Ford CE, DeCarli L, Sereni LP. A case of multiple chromosomal rearrangements with persistence of foetal haemoglobin. Cytogenetics 1968;7:169-82.

${ }^{7}$ Schwinger E, Mikkelsen M, Niesen M. Familial balanced $(7 ; 11 ; 21)$ translocation and Down syndrome in two siblings. Clin Genet 1975;7:304-7.

${ }^{8}$ Palmer CG, Poland C, Reed T, Kojetin J. Partial trisomy $11,46, X X,-3,-20,+\operatorname{der} 3,+\operatorname{der} 20, t(3 ; 11 ; 20)$, resulting from a complex maternal rearrangement of chromosomes $3,11,20$. Hum Genet 1976;31:219-25. 
${ }^{9}$ Dallapiccola B, Bollea G, Mazzilli C, Gandini E. Complex translocation $\mathrm{t}(9 ; 21)(9 ; 22)(\mathrm{q} 12 \mathrm{p} 13)(\mathrm{q} 12 \mathrm{q} 11)$ in the family of a child with 9p trisomy syndrome. Hum Genet 1976;33:73-6.

${ }^{10}$ Muneer RS, Donaldson DL, Rennert OM. Complex balanced translocation of chromosomes 2, 3 and 13. Hum Genet 1981;59:182-4.

1 Hustinx TWJ, Nabben FAE, Scheres JMJC. Partial trisomy of chromosome 1 resulting from a complex maternal rearrangement of chromosome 1, 5 and 6. Am J Med Genet 1979;3:353-8.

12 Tanaka N, Ikeuchi T, Yara I, Kitahara K. Trisomy 9p due to a maternal complex translocation involving chromosomes 4,6 and 9. Jpn J Hum Genet 1977;21:261-8.

${ }^{13}$ Ballesta F, Fernandez E, Mila M. Translocation $t(1 ; 8 ; 15)$ maternelle et trisomie 8qter chez la fille. J Genet Hum 1980;28:361-6.

14 Tabor A, Jensen LK, Lundsteen C, Niebuhr E. A 5;7, 5;12 double reciprocal translocation in a normal mother and a $5 ; 7$ translocation with a recombinant chromosome 5 in her normal child. J Med Genet 1980;17:307-9.

${ }^{15}$ Fredga K, Hall B. A complex familial translocation involving chromosomes 5, 9 and 13. Cytogenetics 1970;9:294-306.
${ }^{16}$ Seabright M, Gregson N, Pacifico E, et al. Rearrangements involving four chromosomes in a child with congenital abnormalities. Cytogenet Cell Genet 1978;20:150-4.

17 Buchana PD, Rao KW, Doerr CL, Aylsworth AS. A complex translocation involving chromsomes 3,11 and 14 with an interstitial deletion, del(14)(q13q22) in a child with congenital glaucoma and cleft lip and palate. Birth Defects 1978;14(6C):317-22.

18 Watt JL, Couzin DA. De novo translocation heterozygote with three reciprocal translocations. J Med Genet 1983;20:385-8.

19 Couzin DA, Watt JL, Auchterlonie IA. A complex double translocation involving four chromosomes and five breakpoints in a child with mild mental retardation. J Med Genet 1983;20: 389-92.

Correspondence and requests for reprints to $\mathrm{Dr}$ M H Bogart, Cytogenetics Laboratory M-013, Division of Medical Genetics, Department of Medicine, University of California, San Diego, La Jolla, California 92093, USA.

\title{
Primary myelodysplastic syndrome with complex chromosomal rearrangements in a patient with Klinefelter's syndrome
}

\author{
S M NAOROSE ABIDI*, M GRIFFITHS $\dagger$, D G OSCIER*, G J MUFTI*, \\ AND T J HAMBLIN* \\ *Department of Haematology, Royal Victoria Hospital, Bournemouth BH1 4JG; and †Wessex Regional \\ Cytogenetics Unit, Salisbury General Hospital, Salisbury SP2 7SX.
}

SUMmARY A patient with Klinefelter's syndrome and diabetes mellitus was diagnosed as having myelodysplasia. Cytogenetic analysis of the peripheral blood and the bone marrow cells confirmed the presence of a constitutional $47, \mathrm{XXY}$ chromosome complement. In addition, complex karyotypic abnormalities were present.

Several studies have suggested an increased incidence of extragonadal germ cell tumours, ${ }^{1}$ carcinoma of the breast, ${ }^{2}$ and acute myeloid leukaemia ${ }^{3-5}$ in patients with Klinefelter's syndrome. In this report we describe a patient with Klinefelter's syndrome who developed a preleukaemic state (myelodysplastic syndrome). Cytogenetic analysis of the bone marrow and peripheral blood of this patient showed a constitutional $47, \mathrm{XXY}$ chromosome complement. In addition, complex karyotypic abnormalities were present. The significance of these findings is discussed.

Received for publication 21 August 1984

Accepted for publication 24 August 1984 .

\section{Case report}

A male Caucasian, aged 68, presented with a four month history of increasing breathlessness. Eight years previously he had been admitted to another hospital in a hyperosmolar, non-ketotic diabetic coma and at that time he was noted to be tall (185 $\mathrm{cm}$ ) and to have hypogonadism and prognathism. $\mathrm{He}$ had been investigated for acromegaly and was found to have raised levels of FSH and $\mathrm{LH}$ and normal levels of TSH, free T4, growth hormone, and prolactin. Skull $x$-ray showed a normal pituitary fossa. His diabetes had been controlled with oral hypoglycaemic agents and the only other drug therapy he had received was testosterone at six monthly intervals. He was unmarried and had no children. He had no history of exposure to chemicals.

On presentation at this hospital he was noted to be pale and lacking facial and body hair. $\mathrm{He}$ had gynaecomastia and small testes. Full blood count showed Hb $7.5 \mathrm{~g} / \mathrm{dl}$, WBC $3.5 \times 10^{9} / 1$ (neutrophils $46 \%$, lymphocytes $45 \%$, monocytes $3 \%$, eosinophils $6 \%$ ), and platelets $309 \times 10^{9} / 1$. Blood film showed dimorphic red cells, hypogranular neutrophils, and platelet anisocytosis. Bone marrow aspirate showed 